\title{
The Economics of Residential Solar Panels: Comparing Tiered and Time of Use Plans
}

\author{
Prashanth U. Nyer, Candace E. Ybarra, John B. Broughton \\ Argyros School of Business \& Economics, Chapman University, Orange, CA, USA \\ Email: nyer@chapman.edu,cybarra@chapman.edu,broughto@chapman.edu
}

How to cite this paper: Nyer, P.U., Ybarra, C.E. and Broughton, J.B. (2020) The Economics of Residential Solar Panels: Comparing Tiered and Time of Use Plans. Open Journal of Business and Management, 8, 56-67.

https://doi.org/10.4236/ojbm.2020.81004

Received: November 5, 2019

Accepted: November 29, 2019

Published: December 2, 2019

Copyright $\odot 2020$ by author(s) and Scientific Research Publishing Inc. This work is licensed under the Creative Commons Attribution International License (CC BY 4.0).

http://creativecommons.org/licenses/by/4.0/ (c) () Open Access

\begin{abstract}
This case study uses data from a Southern California Edison residential customer on a grandfathered tiered rate plan to investigate 1) whether it is economically beneficial for the customer to switch from a tiered-rate plan to a Time-of-Use (TOU) plan, 2) whether going solar now makes financial sense for new solar customers, 3) what level of usage offset (the percentage of the customer's annual electricity consumption that is provided by the solar panels) would result in the maximum financial benefit for the customer under each of the many TOU plans, and 4) whether solar customers on TOU plans can save substantially by time shifting small amounts of electricity usage from peak periods to off peak periods. We find that, by and large, there is no compelling reason for solar customers on the grandfathered tiered rate plans to switch to TOU plans. Solar panels continue to be an excellent investment for customers thinking of going solar, and the ideal usage offset for this customer (and others on TOU rate plans) is in the $103 \%-107 \%$ range. That is, savings are maximized when solar panels produce $103 \%-107 \%$ of the customers' annual electricity consumption. Finally, we find that shifting a modest amount of consumption from peak rate hours to off peak hours during the two months of maximum electricity consumption will result in significant savings.
\end{abstract}

\section{Keywords}

Solar Panels, Net Metering, Sustainability, Discounted Cash Flow, Present Value, Tiered Rate, Time of Use, Avoided Electricity Cost, Savings, Energy

\section{Introduction}

The number of residential solar panel installations in California is increasing substantially from year to year, and solar customers are faced with the choice of 
which of the available net metering programs to enroll under, and which rate plans to choose. In this follow-up paper to Nyer, Broughton \& Ybarra (2019) [1] we use data from the same solar ${ }^{1}$ customer of Southern California Edison to answer the following questions:

1) Should solar customers who are in the grandfathered tiered-rate NEM 1.0 program switch to a Time of Use (TOU) NEM 2.0 plan while the latter is still available?

2) Is it financially worthwhile for a customer to go solar now under the current NEM 2.0 program?

3) What is the ideal usage offset percentage for this customer under the currently available NEM 2.0 rate plans? In other words, what percentage of this customer's electricity consumption should be supplied by solar panels to maximize the customer's savings?

4) To what extent can a customer under a TOU plan reduce his electricity bill by shifting a small percentage of peak-rate consumption to the lowest rate period?

According to the Solar Energy Industry Association, California, with over 970,000 solar installations (47\% of the U.S. total) and 25 Gigawatts $^{2}$ of installed capacity (37\% of the U.S. total), leads the United States in solar installations by a huge margin [2]. The growth of solar installations in the state is managed, in part, by policies determined by the California Public Utilities Commission (CPUC). CPUC's initial policy for solar customers, Net Metering 1.0 (NEM 1.0), set a cap on solar installations for all three investor owned utilities (IOU) in California (Pacific Gas and Electric (PG \& E); San Diego Gas and Electric (SDG \& E); and Southern California Edison (SCE)). Installations were permitted under NEM 1.0 until five percent of the total peak electrical demand in the region was provided by solar or until June 30, 2017, whichever came first. The three IOUs together supply approximately three quarters of the electricity in California [3]. SDG \& E reached the NEM 1.0 limit by June 2016, and PG \& E by December 2016. SCE did not reach the five percent threshold and stopped adding new solar customers to the NEM 1.0 program by the end of June 2017 [4]. Customers who received permission to turn on their solar panel systems after these cut off dates were enrolled in the successor program called Net Metering 2.0 (NEM 2.0). The NEM 2.0 program is expected to expire in the fourth quarter of 2020, after which new solar customers will be enrolled in the NEM 3.0 program whose details are yet to be finalized.

In a nutshell, net metering refers to programs where customers with solar panels have electricity meters that run both ways. When the sun is shining and the solar panels are producing more energy than the customer is using, the excess energy is sent to the grid and the meter runs backwards. At other times when the customer is using more energy than is being produced by the solar panels (for example at

${ }^{1}$ All references to "solar" in this article refer to solar photo-voltaic projects and not to other technologies such as solar thermal projects.

${ }^{2}$ One Gigawatt $(\mathrm{GW})$ is equal to one billion Watts or 1000 kilowatts $(\mathrm{kW})$. 
night, and on cloudy days) the meter runs forward and registers the energy that the customer is drawing from the grid. The customer is billed for the net energy drawn from net energy drawn from the grid, i.e., the net metered amount.

\section{NEM 1.0 vs. NEM 2.0}

The NEM 1.0 program, which was limited to no more than five percent of the peak demand in each utility's territory, gave customers the option to be grandfathered into their tiered rate plans for 20 years. Under NEM 2.0 customers had to choose from a few different time of use (TOU) plans, and could not continue on the old tiered rate plan. In addition, NEM 2.0 allowed utilities to change the way non-bypassable charges were computed. These charges cover the costs of decommissioning nuclear power plants, financing bonds, and funding programs for low income customers. These charges cannot be offset by any excess energy produced by the customer, and the net effect of the non-bypassable charges under NEM 2.0 was to increase the customers' cost by 2-3 cents per kilowatt hour (a unit of energy equivalent to running a 1000 Watt appliance for one hour; abbreviated kWh). Finally, as opposed to the NEM 1.0 program, customers under NEM 2.0 had to pay a one-time interconnection fee that amounted to $\$ 145$ for PG \& E customers, $\$ 132$ for SDG \& E customers and \$75 for SCE customers [4].

\section{TOU vs. Tiered Rate Plans ${ }^{3}$}

Under a TOU rate plan the utility company charges different rates for electricity depending on the time of use. Charges are usually higher during those hours of the day when the demand for electricity from the grid is higher, and charges are lower when the demand on the grid is lower. In contrast, under a tiered rate plan, charges are the same rate regardless of the time-of-day, but the customer pays more per unit of electricity when their monthly consumption exceeds certain baseline limits. Thus, in a tiered rate plan, the customer pays a low rate per $\mathrm{kWh}$ for their monthly electricity consumption in tier 1 , up to the tier 1 baseline limit which is determined by the customer's climatic region and the season of the year. Once the customer's monthly electricity consumption exceeds the baseline limit (and until it reaches four times the baseline amount), the excess consumption is charged at the tier 2 rates that are significantly higher. Any consumption that exceeds the tier 2 limit is charged at an even higher rate.

Whether a solar customer is on a tiered rate plan or a TOU plan can have a significant impact on his electricity bill because of the way net metering works. As an example, assume the solar panel array of a customer on a tiered rate plan sends $5 \mathrm{kWh}$ of excess energy to the grid during the daylight hours. Further assume that after the sun has set, the customer draws $5 \mathrm{kWh}$ of energy from the grid. The customer has thus drawn a net total of zero kWh for the day. For this tiered rate plan customer, one unit of electricity sent to the grid or drawn from

${ }^{3}$ The numbers mentioned here may be specific to Southern California Edison, but are fairly representative of all California IOUs. 
the grid is credited/billed at the same rate regardless of the time of day. In contrast, TOU customers are credited or billed different amounts for the energy sent to/ drawn from the grid depending on the time of day. If the utility charges a high rate for energy during the day light hours, and a low rate during the evening and night hours then the hypothetical TOU customer in the above example would come out ahead for the day since the $5 \mathrm{kWh}$ sent to the grid during the day would be worth more than the $5 \mathrm{kWh}$ drawn from the grid at night. On the other hand, as is typically the case, if the utilities charge less for energy during the daylight hours and more during the evening hours then the customer in the example above would find the excess solar energy sent to the grid to be worth less than the energy drawn from the grid in the evening.

With NEM 2.0 soon coming to an end (it is expected to be replaced by NEM 3.0 in Q4 2020), many of the over 550,000 residential solar customers in California currently on the NEM 1.0 program [5] are surely wondering whether they would be better off staying with the tiered rate plan in NEM 1.0 or whether they should switch to one of the TOU plans in NEM 2.0 while those plans are still available. It is widely speculated that NEM 3.0 rules will be less favorable to new solar customers than the current NEM 2.0 rules [6], and therefore this is a decision that many NEM 1.0 customers will have to make soon. Further, does it still make sense for non-solar customers to get into solar now, under the NEM 2.0 program? And if so, what is the ideal usage offset percentage (the percentage of the customer's consumption that is supplied by solar) that will maximize the customer's savings under the NEM 2.0 program? Finally, to what extent can a customer on a TOU plan reduce his electricity bill by shifting a small percentage of peak-rate consumption to the lowest rate period of the day?

\section{Research Method}

To answer these questions, we re-visit the solar installation of Ruth Singer (see Nyer, Broughton \& Ybarra, 2019) [1], the residential SCE customer who went solar in early 2017 and who is currently grandfathered under the NEM 1.0 tiered-rate program. It cost Ruth $\$ 9082.50$ (after the $30 \%$ federal tax credit) to have $14 \mathrm{LG}$ solar panels (with a stated capacity of $3.99 \mathrm{~kW} \mathrm{DC}$ ) installed on the west facing roof plane of her house in Orange, California. We used the detailed electricity rates published by SCE (for various rate plans and for different time periods), the net-purchase of electricity from SCE (available in 15 minute intervals from the SCE portal), and the production of solar electricity (available in hourly increments from the app provided by the micro-inverter manufacturer) for an entire year to determine the answers to the research questions we listed in the Introduction section. Further information regarding this customer and the calculations done here can be found in Nyer, Broughton \& Ybarra (2019) [1].

\subsection{Comparing Tiered Rate to Time of Use}

Over the years SCE has offered many TOU plans, some of which are no longer 
available to new customers (but are available for $n o w^{4}$ to those who are grandfathered into those plans). Table 1 summarizes the major differences between the four TOU plans examined in these analyses. As in the past, SCE currently offers additional TOU plans that are only available to customers who own electric vehicles, storage batteries or electric pumps. Since Ruth Singer does not have any of these, those plans are not included in these analyses. Table 1 includes the price per kWh for each of these rate plans as of August 2019. These prices are shown for illustrative purposes only since the price changes multiple times each year. The analyses done in this paper use the actual price of energy charged by SCE for each day of the year.

Table 1. Major differences in the TOU plans. (The approximate price per kWh for August 2019 has been included for illustration).

\begin{tabular}{|c|c|c|c|c|}
\hline & TOU-A & TOU-B & TOU 4 - 9 & TOU 5 - 8 \\
\hline & \multicolumn{4}{|c|}{ Summer Weekdays (June through September) } \\
\hline On Peak & $2 \mathrm{pm}-8 \mathrm{pm}(\$ 0.52)$ & $2 \mathrm{pm}-8 \mathrm{pm}(\$ 0.48)$ & $4 \mathrm{pm}-9 \mathrm{pm}(\$ 0.41)$ & $5 \mathrm{pm}-8 \mathrm{pm}(\$ 0.49)$ \\
\hline Off Peak & $8 \mathrm{am}-2 \mathrm{pm} \& 8 \mathrm{pm}-10 \mathrm{pm}(\$ 0.28)$ & $8 \mathrm{am}-2 \mathrm{pm} \& 8 \mathrm{pm}-10 \mathrm{pm}(\$ 0.16)$ & $9 \mathrm{pm}-4 \mathrm{pm}(\$ 0.22)$ & $8 \mathrm{pm}-5 \mathrm{pm}(\$ 0.23)$ \\
\hline \multirow[t]{2}{*}{ Super Off Peak } & $10 \mathrm{pm}-8 \mathrm{am}(\$ 0.13)$ & $10 \mathrm{pm}-8 \mathrm{am}(\$ 0.10)$ & - & - \\
\hline & \multicolumn{4}{|c|}{ Summer Weekends \& Holidays (June through September) } \\
\hline Mid Peak & - & - & 4 pm-9 pm $(\$ 0.27)$ & $5 \mathrm{pm}-8 \mathrm{pm}(\$ 0.29)$ \\
\hline Off Peak & $8 \mathrm{am}-10 \mathrm{pm}(\$ 0.28)$ & $8 \mathrm{am}-10 \mathrm{pm}(\$ 0.16)$ & $9 \mathrm{pm}-4 \mathrm{pm}(\$ 0.22)$ & $8 \mathrm{pm}-5 \mathrm{pm}(\$ 0.23)$ \\
\hline \multirow[t]{2}{*}{ Super Off Peak } & $10 \mathrm{pm}-8 \mathrm{am}(\$ 0.13)$ & 10 pm-8 am $(\$ 0.10)$ & - & - \\
\hline & \multicolumn{4}{|c|}{ Winter Weekdays (October through May) } \\
\hline On Peak & $2 \mathrm{pm}-8 \mathrm{pm}(\$ 0.34)$ & $2 \mathrm{pm}-8 \mathrm{pm}(\$ 0.24)$ & - & - \\
\hline Mid Peak & - & - & 4 pm-9 pm $(\$ 0.29)$ & 5 pm-8 pm $(\$ 0.30)$ \\
\hline Off Peak & 8 am-2 pm \& 8 pm-10 pm (\$0.25) & 8 am-2 pm \& 8 pm-10 pm $(\$ 0.15)$ & 9 pm-8 am $(\$ 0.28)$ & $8 \mathrm{pm}-8$ am $(\$ 0.29)$ \\
\hline \multirow[t]{2}{*}{ Super Off Peak } & 10 pm-8 am $(\$ 0.13)$ & $10 \mathrm{pm}-8 \mathrm{am}(\$ 0.11)$ & $8 \mathrm{am}-4 \mathrm{pm}(\$ 0.17)$ & 8 am-5 pm $(\$ 0.17)$ \\
\hline & \multicolumn{4}{|c|}{ Winter Weekends \& Holidays (October through May) } \\
\hline Mid Peak & - & - & $4 \mathrm{pm}-9 \mathrm{pm}(\$ 0.29)$ & 5 pm-8 pm $(\$ 0.30)$ \\
\hline Off Peak & $8 \mathrm{am}-10 \mathrm{pm}(\$ 0.25)$ & $8 \mathrm{am}-10 \mathrm{pm}(\$ 0.15)$ & 9 pm-8 am $(\$ 0.28)$ & $8 \mathrm{pm}-8$ am $(\$ 0.29)$ \\
\hline Super Off Peak & $10 \mathrm{pm}-8 \mathrm{am}(\$ 0.13)$ & $10 \mathrm{pm}-8 \mathrm{am}(\$ 0.11)$ & $8 \mathrm{am}-4 \mathrm{pm}(\$ 0.17)$ & 8 am-5 pm $(\$ 0.17)$ \\
\hline $\begin{array}{c}\text { Baseline Credit } \\
\text { (per kWh upto } \\
\text { baseline allocation) }\end{array}$ & $\$ 0.07$ & - & $\$ 0.07$ & $\$ 0.07$ \\
\hline Daily basic charge & 0.03 & $\$ 0.50$ & $\$ 0.03$ & $\$ 0.03$ \\
\hline Daily minimum charge & $\$ 0.35$ & - & $\$ 0.35$ & $\$ 0.35$ \\
\hline
\end{tabular}

${ }^{4}$ Solar customers on the grandfathered TOU D-A or TOU D-B plans will be able to stay on these plans for five years from the date of their initial Permission to Operate (PTO) or until July 31, 2022 whichever comes first. After that they will have to switch to a TOU plan that is then being offered to the customers. 
From Table 1, it is obvious that, compared to older TOU plans (TOU-A and TOU-B), SCE's current TOU plans (the $4-9$ and the $5-8$ plans) have peak hours that start much later in the day and for the most part are hours when solar panels are not producing much energy. The TOU-A and TOU-B plans were available until February 2019, and customers going solar starting March 1, 2019 had to enroll in the newer 4 - 9 or 5 - 8 plans. These newer plans are less attractive compared to the older TOU plans for solar customers since most of the solar energy will be produced at times when rates are lower, and much of the energy consumption will take place (usually between the times when people return home from work and when they go to bed) when the rates are higher.

As explained in Nyer, Broughton \& Ybarra (2019) [1], this customer consumed $9030.49 \mathrm{kWh}$ for the billing year ending mid-August 2019, while producing $5421.38 \mathrm{kWh}$ of solar energy during the same period, resulting in her purchasing $3609 \mathrm{kWh}$ of energy from SCE during the year. Using the customer's detailed energy consumption data from SCE (available in 15-minute intervals for the whole year), and hourly solar production data from the solar panel array for the entire year, we estimated the effective annual cost of electricity for this customer under different SCE tariff rates: the client's current tiered rate plan, the older TOU-A and TOU-B plans, and the currently available TOU 4 - 9 and TOU 5 - 8 plans. Table 2 reports effective annual cost of electricity, avoided cost compared to no solar panels, net present value (NPV), and internal rate of return for each tariff rate regime. NPV is the discounted present value of the avoided costs over twenty-five years less the cost of the solar panels net of the federal tax credit (\$9082.50). While the solar panel systems are expected to last beyond their warrantied life of 25 years, we chose to be conservative and to calculate the avoided costs for just twenty-five years. An important issue in calculating the NPV of a stream of cash flows (or in this case, avoided costs) is determining the appropriate discount rate to use. Ruth, who had paid for the solar

Table 2. Net present value and internal rate of return for different rate plans.

\begin{tabular}{|c|c|c|c|c|c|c|}
\hline & $\begin{array}{c}\text { Tiered rate then } \\
\text { TOU } 5-8^{\mathrm{a}}\end{array}$ & $\begin{array}{l}\text { TOU-A then } \\
\text { TOU } 5-8^{\mathrm{b}}\end{array}$ & $\begin{array}{l}\text { TOU-B then } \\
\text { TOU } 5-8^{\mathrm{b}}\end{array}$ & TOU 4 - 9 & TOU $5-8$ & Without Solar \\
\hline Annual effective SCE cost & $\$ 685.84$ & $\$ 432.81$ & $\$ 754.16$ & $\$ 856.84$ & $\$ 836.24$ & $\$ 1895.86$ \\
\hline Annual avoided SCE cost & $\$ 1210.02$ & $\$ 1463.05$ & $\$ 1141.70$ & $\$ 1039.02$ & $\$ 1059.62$ & - \\
\hline 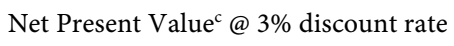 & $\$ 11,606.39$ & $\$ 11,216.41$ & $\$ 9744.72$ & $\$ 9010.11$ & $\$ 9368.82$ & - \\
\hline Net Present Value $^{c} @$ 6\% discount rate & $\$ 6188.08$ & $\$ 6162.39$ & $\$ 4808.75$ & $\$ 4199.66$ & $\$ 4463.00$ & - \\
\hline 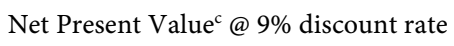 & $\$ 2698.64$ & $\$ 2894.90$ & $\$ 1644.96$ & $\$ 1123.36$ & $\$ 1325.70$ & - \\
\hline Internal Rate of Return & $12.56 \%$ & $13.19 \%$ & $11.22 \%$ & $10.50 \%$ & $10.76 \%$ & - \\
\hline
\end{tabular}

a Since the tiered rate is available for only 20 years, the net present value assumes that the customer will be switched to the next best rate (TOU 5 - 8 ) for years 21-25. b Since the TOU-A and TOU-B plans will become unavailable after 5 years from PTO or beyond July 31,2022 whichever comes first, these calculations assume that the TOU-A and TOU-B rates are available for the first 5 years after which the customer has to switch to the next best available plan (TOU 5 - 8) for the remaining 20 years. c Net Present Value is the present value of the avoided SCE costs for 25 years less the cost of the solar panels after the federal tax credit $(\$ 9082.50)$. 
panels upfront, could have financed the panels through an installer at a rate of approximately $5 \%-6 \%$. Thus, she believed that a discount rate of $5 \%-6 \%$ was appropriate for computing NPV. Ruth also calculated the internal rate of return (IRR) for each rate plan. The IRR is the discount rate that results in the present value of the cash flows (the avoided costs) equaling the initial investment. It is loosely interpreted as the expected return on the investment. The tiered rate plan, which Ruth is currently under, will be available to her for a total of 20 years from the date her solar panels went online. After that time she will be required to switch to a then available TOU plan. Therefore, to calculate the NPV and IRR for the tiered plan, we used the cash flows from the tiered rate plan for the first 20 years and then the cash flows from the TOU $5-8$ plan for the remaining five years (since the TOU 5 - 8 plan resulted in more savings compared to the TOU 4 - 9 plan with the currently installed system and with the customer's current consumption profile: see the first row in Table 3) Similarly, the TOU-A and TOU-B rate plans, which are no longer available to new customers, have been grandfathered for solar customers who went solar between July 1, 2017 and February 28, 2019. These plans will be available to these customers until July 31, 2022 at the latest. To calculate the NPV and IRR for TOU-A and TOU-B customers we used the TOU-A and TOU-B rates for the first five years, and then the next best available rate plan (TOU $5-8$ ) for the remaining 20 years.

Table 3. The ideal usage offset percentage under various rate plans.

\begin{tabular}{|c|c|c|c|c|c|}
\hline \multicolumn{6}{|c|}{ Net Present Value of Savings } \\
\hline Usage offset \% & Tiered & TOU 4 - 9 & TOU 5 - 8 & $\begin{array}{l}\text { TOU A then } \\
\text { TOU } 5-8\end{array}$ & $\begin{array}{c}\text { TOU B then } \\
\text { TOU } 5 \text { - } 8\end{array}$ \\
\hline $60.03 \%$ & $\$ 6385.62$ & $\$ 4199.66$ & $\$ 4463.00$ & $\$ 6162.39$ & $\$ 4808.75$ \\
\hline $64.32 \%$ & $\$ 6713.96$ & $\$ 4471.38$ & $\$ 4683.58$ & $\$ 6598.19$ & $\$ 5175.67$ \\
\hline $68.61 \%$ & $\$ 7074.45$ & $\$ 4828.42$ & $\$ 4982.59$ & $\$ 7076.34$ & $\$ 5599.53$ \\
\hline $72.90 \%$ & $\$ 7478.60$ & $\$ 5197.41$ & $\$ 5293.54$ & $\$ 6969.09$ & $\$ 6035.29$ \\
\hline $77.19 \%$ & $\$ 7899.81$ & $\$ 5578.61$ & $\$ 5616.58$ & $\$ 7059.02$ & $\$ 6483.23$ \\
\hline $81.47 \%$ & $\$ 8329.67$ & $\$ 5944.04$ & $\$ 5923.84$ & $\$ 7149.18$ & $\$ 6924.70$ \\
\hline $85.76 \%$ & $\$ 8720.64$ & $\$ 6300.49$ & $\$ 6216.12$ & $\$ 7236.31$ & $\$ 6696.16$ \\
\hline $90.05 \%$ & $\$ 9072.09$ & $\$ 6649.51$ & $\$ 6511.07$ & $\$ 7322.03$ & $\$ 6789.04$ \\
\hline $94.34 \%$ & $\$ 9401.82$ & $\$ 7020.67$ & $\$ 6828.53$ & $\$ 7416.83$ & $\$ 6900.19$ \\
\hline $98.63 \%$ & $\$ 9732.37$ & $\$ 7427.28$ & $\$ 7180.43$ & $\$ 7538.02$ & $\$ 7037.67$ \\
\hline $102.92 \%$ & $\$ 9504.24$ & $\$ 7875.26$ & $\$ 7564.49$ & $\$ 7687.58$ & $\$ 7200.67$ \\
\hline $107.20 \%$ & $\$ 9226.11$ & $\$ 7821.99$ & $\$ 7811.00$ & $\$ 7742.80$ & $\$ 7275.77$ \\
\hline $111.49 \%$ & $\$ 8914.02$ & $\$ 7514.50$ & $\$ 7503.50$ & $\$ 7419.97$ & $\$ 6981.59$ \\
\hline $115.78 \%$ & $\$ 8599.58$ & $\$ 7215.78$ & $\$ 7208.24$ & $\$ 7097.29$ & $\$ 6699.68$ \\
\hline
\end{tabular}




\subsection{Switch to TOU or Stay on Tiered Rate?}

As shown in Table 2, customers who went solar early and who are on a tiered rate plan (IRR $=12.56 \%)$ or on the TOU-A plan (IRR $=13.19 \%)$ will save more money than customers in the other plans, but even the worst of the plans examined in this study has an IRR close to $10.50 \%$. One thing that becomes clear from this analysis is that regardless of the rate plan being used, solar panels generate a net savings. The savings from having solar panels have low volatility, and even the lowest estimated IRR of $10.50 \%$ compares favorably with the average annual returns from the stock market, especially considering the high volatility associated with the stock market. The TOU plan that made the most economic sense to Ruth was the TOU-A plan which became unavailable for enrollment starting March 1, 2019. If Ruth had switched to the TOU-A plan as soon as she got her solar panels, she would have enjoyed a slightly higher IRR than by staying with the tiered rate plan. However, assuming a discount rate of $3 \%$ or $6 \%$, her savings, and thus NPV, would have been higher with the tiered rate plan. Consequently, there was no compelling reason for Ruth to have switched to the TOU-A plan. Now that the TOU-A plan has been replaced with the TOU 4 - 9 and 5 - 8 plans, which are less advantageous for the customer, there is no reason for Ruth to switch to a TOU plan. Further, being on a TOU plan requires the customer to be mindful of when she is consuming energy, while being on a tiered rate plan provides the customer the flexibility to consume electricity at any time of the day without worrying about hitting peak rates.

In conclusion, customers on the grandfathered tiered rate plan are best served by staying on that plan until their grandfathering period expires 20 years after PTO (since they can no longer switch to the TOU-A plan). Customers on the TOU-A and TOU-B plans will be forced to switch to another TOU plan that is available by July 2022, at which time they should choose the plan that saves them the most money.

A troubling trend is that each successive Net Metering program and the rate plans being offered by the utilities are becoming less attractive to new solar installations. The soon to be unveiled Net Metering 3.0 program is expected to be even less attractive to new solar customers than its predecessor program. We believe that the current trends in rate plans will encourage future solar customers to also install battery storage; but that is a topic that we will explore in a future paper.

\subsection{What Is the Ideal Usage Offset?}

The usage offset refers to the percentage of the customer's electrical energy consumption that is provided by the customer's solar panel array. Nyer, Broughton \& Ybarra (2019) [1] determined that for customers on SCE's tiered rate plan, the ideal usage offset (the one that maximizes NPV or the difference between the present value of the avoided electricity bills over 25 years and the cost of the solar panels) was $100 \%$. Thus customers on the tiered rate plan would have been 
best served by installing solar panels that produce as much electrical energy each year as the customer's annual consumption. However, TOU plans work differently, and we investigated the ideal usage offset for this customer for various TOU plans offered by SCE. The results are presented in Table 3.

While Ruth Singer had chosen a 14 panel array (which cost her $\$ 9082.50$ after the $30 \%$ federal tax credit), she had received quotes from installers for arrays with more panels. Based on that information, and discussions with solar installers she determined that each additional panel beyond the $14^{\text {th }}$ could be obtained at $98 \%$ of the cost of the previous installed panel. Thus, while the first 14 panels had cost her an average of $\$ 648.75$ ( $\$ 9082.50 / 14)$, she estimated that she could have obtained the $15^{\text {th }}$ panel for $\$ 635.78(\$ 648.75 \times 0.98)$, the $16^{\text {th }}$ panel for $\$ 623.06$ ( $\$ 635.78 \times 0.98)$ etc. Using this information, we estimated the cost of solar panel arrays with 14 to 27 panels (usage offset ranging from approximately $60 \%$ to $116 \%$ ). We assumed that the solar panel production would scale linearly with the size of the array provided all the panels were installed on the same roof face. Using detailed 15-minute interval usage data provided by SCE and hourly production data provided by the solar panel system, we estimated the annual avoided SCE costs for solar panel arrays of various sizes and under various rate plans. We calculated the present value of the SCE costs avoided assuming that the customer would be able to realize annual SCE avoided costs for 25 years (the length of the system warranty). The NPV (the present value of the SCE costs avoided over 25 years less the cost of the solar panels) was calculated using discount rates of $3 \%, 6 \%$ and $9 \%$ and the pattern of findings were almost the same at all values of the discount rate. In the interest of brevity, we limit Table 3 to the NPVs calculated using the discount rate of $6 \%$.

As discussed earlier, the TOU-A and TOU-B rate plans are not available to new customers, and customers who are on these plans can be on them for a maximum of five years or until July 31, 2022 whichever comes first. The figures in Table 3 assume that customers on the TOU-A and TOU-B rate plans will be on those plans for five years and then switch to the next best plan that is currently available - the TOU 5 - 8 plan - for the remaining 20 years. Similarly, we assumed that customers on the old tiered rate plan would be able to stay on that plan for only 20 years and then have to switch to a TOU plan (TOU 5 - 8). In each of the columns in Table 3, the number that is highlighted represents the maximum NPV for that rate plan. The ideal offset percentage for the various TOU plans is just over $100 \%$. While it is not shown in Table 3, the ideal usage offset for the TOU-A and TOU-B plans would have been very different had this customer been able to hold on to those plans for 25 years. For TOU-A the ideal offset would have been approximately $70 \%$ and for TOU-B it would have been approximately $80 \%$. Note that these calculations are based on the usage patterns and the solar production data for this specific customer. However, we believe that the usage offset recommendations we make here are widely applicable.

The conclusion we can draw here is that SCE customers thinking of going solar now will be best served by having a solar panel array that offsets approx- 
imately $103 \%$ - 107\% of their expected annual electricity usage.

\subsection{Does Time Shifting Peak Load Save Money?}

TOU plans incentivize customers to shift some of the electricity use from when the rates are at the peak levels (for example SCE charges $\$ 0.52$ per kWh during peak hours on summer weekdays under the TOU-A plan) to times when the rates are lower (for example after $10 \mathrm{PM}$ when the SCE rate for the same rate plan is only $\$ 0.13$ per $\mathrm{kWh}$.) While customers may find it challenging to shift a lot of their electricity usage by a few hours, many customers should be able to achieve modest time shifting of electricity use. ${ }^{5}$ Figure 1 shows the daily electricity consumption for this customer between 5 PM and 8 PM over the course of a year. The consumption during the hours between 5 PM and $8 \mathrm{PM}$ is highest for the billing months starting mid-July and mid-August. In this section we investigate the financial impact of shifting a mere two kWh of electricity use every evening during these two months from the peak time (between 5 PM and 8 PM) to after 10 PM. We chose the peak hours of 5 PM to $8 \mathrm{PM}$ since that time period is in the peak rate period under all SCE TOU plans considered in this paper. Two kWh is a very modest amount of electricity use; to put this into perspective, a load of laundry (washer and dryer) may consume $5 \mathrm{kWh}$, while a dishwasher may consume $1.5 \mathrm{kWh}$ of energy. Appliances such as these now usually have settings where one can load the machines and program them to run after a delay of a few hours thereby making time shifting of electricity use relatively easy. Table 4, which summarizes the results of this analysis, is identical to Table 2 except for the fact that $2 \mathrm{kWh}$ of energy use has been shifted from the peak rate period to after 10 PM during two summer months. Comparing the NPVs in Table 4 with those in Table 2, we see that the customer will benefit by shifting electricity

Table 4. Impact of Slight Time Shifting of Peak Load on Net Present Value and Internal Rate of Return (compare with Table 2).

\begin{tabular}{|c|c|c|c|c|c|c|}
\hline & $\begin{array}{l}\text { Tiered Rate then } \\
\text { TOU } 5-8^{\mathrm{a}}\end{array}$ & $\begin{array}{l}\text { TOU-A then } \\
\text { TOU } 5-8^{\mathrm{b}}\end{array}$ & $\begin{array}{l}\text { TOU-B then } \\
\text { TOU } 5-8^{\mathrm{b}}\end{array}$ & TOU 4 - 9 & TOU 5 - 8 & $\begin{array}{l}\text { Without } \\
\text { Solar }\end{array}$ \\
\hline Annual effective SCE cost & $\$ 685.84$ & $\$ 389.83$ & $\$ 715.32$ & $\$ 839.80$ & $\$ 813.13$ & $\$ 1895.86$ \\
\hline Annual avoided SCE cost & $\$ 1210.02$ & $\$ 1506.03$ & $\$ 1180.54$ & $\$ 1056.06$ & $\$ 1082.73$ & - \\
\hline Net present value`@3\% discount rate & $\$ 11,664.99$ & $\$ 11,709.83$ & $\$ 10,219.18$ & $\$ 9306.83$ & $\$ 9771.24$ & - \\
\hline Net present value $@ 6 \%$ discount rate & $\$ 6218.43$ & $\$ 6541.52$ & $\$ 5170.43$ & $\$ 4417.49$ & $\$ 4758.42$ & - \\
\hline Net present value $@ 9 \%$ discount rate & $\$ 2714.67$ & $\$ 3199.19$ & $\$ 1933.15$ & $\$ 1290.73$ & $\$ 1552.70$ & - \\
\hline Internal Rate of Return & $12.57 \%$ & $13.63 \%$ & $11.61 \%$ & $10.71 \%$ & $11.05 \%$ & - \\
\hline
\end{tabular}

a Since the tiered rate is available for only 20 years, the calculation assumes that the customer will be switched to the next best rate (TOU 5 - 8 ) for years 21-25. b Since the TOU-A and TOU-B plans will become unavailable after 5 years from PTO or beyond July 31,2022 whichever comes first, these calculations assume that the TOU-A and TOU-B rates are available for the first 5 years after which the customer has to switch to the next best available plan (TOU 5 - 8) for the remaining 20 years. c Net present value is the present value of the avoided SCE costs for 25 years less the cost of the solar panels after the federal tax credit $(\$ 9082.50)$

\footnotetext{
${ }^{5}$ Customers who own electric vehicles can easily time shift a lot of their electricity use to when the rates are the lowest, but since electric vehicles are still uncommon, we will not consider that in this paper.
} 


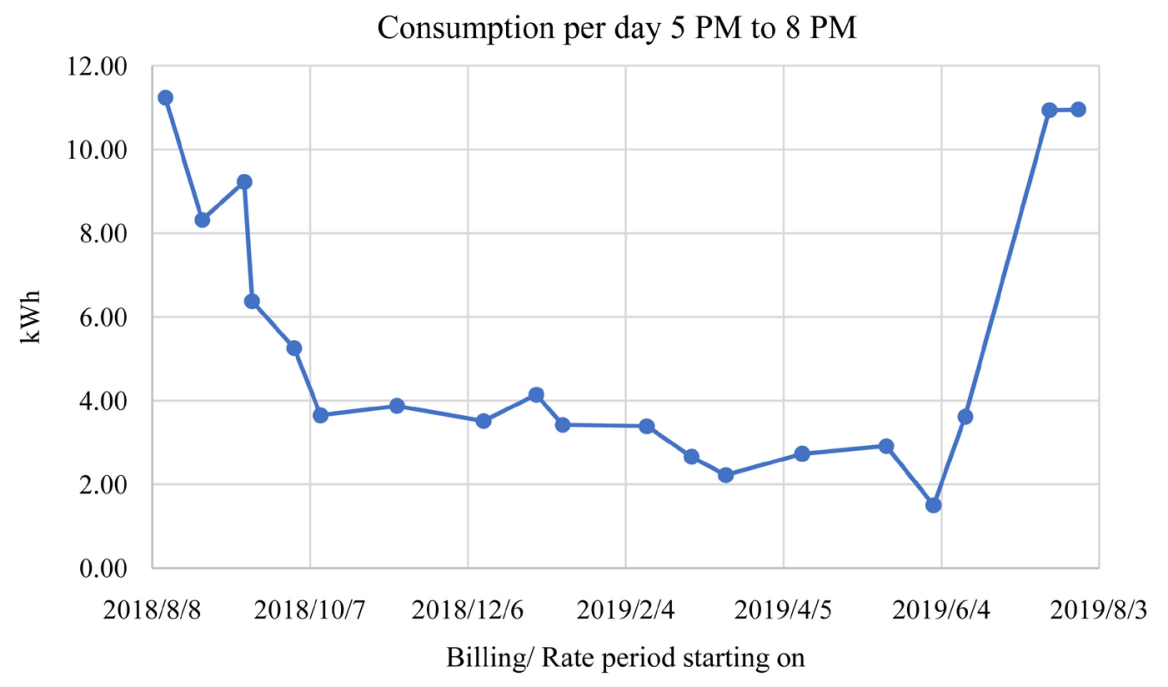

Figure 1. Daily consumption between 5 PM and 8 PM.

usage under all TOU plans. For example, with the TOU 5 - 8 rate plan the NPV (over 25 years, at a discount rate of $6 \%$ ) increases from $\$ 4,463.00$ to $\$ 4758.42$, a $6.62 \%$ increase. Shifting a larger percentage of electrical use from peak rate periods to low rate periods will yield greater savings, and at the same time result in lower stress on the grid. As the difference between the highest and the lowest rates increases, customers will be more likely to shift some of their electricity usage to lower rate time periods, and/or use battery storage to engage in energy arbitrage buying energy from the grid and storing the energy in batteries when the rates are lower, and then selling the stored energy or using it up when the rates are the highest.

\section{Conclusions}

Our findings indicate that solar customers who are on SCE's grandfathered tiered rate plan have no reason to shift to a TOU plan now. Customers who are currently grandfathered into the old TOU-A and TOU-B plans will be forced to choose another plan by July 1, 2022 (or five years from the date of the initial PTO, whichever comes first), and at that time they should choose one of the the available plans. With each passing NEM program, program terms and rate plans are becoming less attractive to solar customers. However, solar customers can still save substantially under all current rate plans. With the federal tax incentives scheduled to decrease in the coming years, now is a good time to go solar.

The ideal usage offset for customers on TOU plans is just over $100 \%$. Thus, customers going solar now may want to select a system that produces $103 \%$ $107 \%$ of the expected annual electricity consumption. As stated by Nyer, Broughton \& Ybarra (2019) [1], customers thinking of going solar should try to estimate their future electrical needs rather than getting their systems sized merely based on the last 12 months of electrical usage.

We find that shifting even a modest amount of electricity usage from the peak 
rate period to a later time period will result in significant savings. Suggestions for doing this include running the dishwasher and laundry appliances at night and charging electric vehicles outside the peak rate period.

While this study was based on data from one residential customer, our findings were generalizable. However, we believe it is a good idea to repeat these analyses with other customers with different usage profiles. Another topic that deserves attention is the impact of the yet-to-be-announced NEM 3.0 on solar savings. With battery storage becoming less expensive, more attention needs to be paid to the financial implications of combining battery storage with solar panels, or even just having battery storage.

\section{Conflicts of Interest}

The authors declare no conflicts of interest regarding the publication of this paper.

\section{References}

[1] Nyer, P.U., Broughton, J.B. and Ybarra, C.E. (2019) The Economics of Residential Solar Panel Installations for Customers on Tiered Rate Plans. Open Journal of Business and Management, 7, 1999-2008. https://doi.org/10.4236/ojbm.2019.74137

[2] Solar Energy Industries Association (2019) Solar State by State. https://www.seia.org/states-map

[3] California Energy Commission (2019) Differences between Publicly and Investor Owned Utilities.

https://ww2.energy.ca.gov/pou reporting/background/difference_pou iou.html

[4] California Public Utilities Commission (2019) Net Energy Metering (NEM). https://www.cpuc.ca.gov/General.aspx?id=3800

[5] California Distributed Generation Statistics (2019) Distributed Generation Interconnection Program Data.

https://www.californiadgstats.ca.gov/downloads/\#_nem cids

[6] Christensen, E. (2019) A Guide to Grandfathering Protections for Solar Customers. https://www.energytoolbase.com/newsroom/blog/grandfathering-protections-for-s olar-customers 